\title{
Implementation of 3PL Service Providers' Efficient Reverse Logistics Management System
}

\author{
Doo-Jin Park \\ Department of Port Logistics System, Tongmyong University, \\ Busan, 48520, South Korea \\ djpark@tu.ac.kr
}

\begin{abstract}
This study suggests the method of structuring reverse logistics systems for 3PL firms. To make the systems, this study performs data analysis and process analysis on the basis of the requirements of 3PL reverse logistics systems. The step of the data analysis is connected with designing and structuring of the database after processing data modeling. The step of analyzing the process deals with making applications after designing applications and modeling the process. In order to simultaneously consider data analysis and process analysis, these studies utilize the whole 3PL reverse logistics systems.

It is possible for structured $3 P L$ reverse logistics systems to save logistical cost and improve customer service through decreasing lead time on reverse logistics. The systems can guarantee the allocation of stable benefits for both manufacturers and $3 P L$ service providers.
\end{abstract}

Keywords: Third Party Logistics (TPL, 3PL), Service Providers, Reverse Logistics

\section{Introduction}

Recently, manufacturers changed the method of operations management from small products, mass production and mass transport to multi-products, small production and frequent delivery due to customer needs that are different and segmented. Traditional value chain is connected from manufacturers to final customers by way of distributors. There are various physical distribution systems including manufacturers, distributors, wholesalers and retailers. Because of the high levels of customer needs, there is a variety of changes within the distribution channels. When customers choose goods, they require and desire better changes such as improved customer services as well as cost competitiveness. The logistics outsourcing sector on the basis of electronic commerce responds to this requirement very adequately. The market of electronic commerce has grown in the niche market between wholesalers and retailers but it is rapidly growing on the basis of the high levels of customer needs and development of information technology. The frequency of using 3PL (3rd party logistics, TPL) has been increasing because of dramatic development in electronic commerce such as cross-border online shipping and reverse cross-border online shipping $[1,2]$.

From the viewpoint of logistics in electronic commerce, there is a high level of logistics cost in the prime cost compared with off-line transaction and as a result, efficient logistics management is needed. In addition, due to the characteristic of electronic commerce such as non-face-to-face transaction, there are frequent exchanges or returns of goods. Customers who bought goods via electronic commerce would exchange or return the goods because of various reasons such as color, design, change of mind, terms of product service and/or damage. This is connected with reverse logistics which is the process of moving the goods from customers back to manufacturers. Logistics is defined

Received (April 16, 2018), Review Result (June 3, 2018), Accepted (June 10, 2018) 
as the process in which goods move from manufacturers to customers, and reverse logistics is defined as the process in which goods move from customers to manufacturers [3]. The following are the two steps for reverse logistics processes. In the first step, the customers call the customer service center requesting the return of the goods, and the center receives the request for returned goods. Next, the logistics service providers recover the goods, and they are returned to the logistics center. In the second step, the staff of manufacturers at the logistics centers examines the returned goods and re-adjusts the grade on the basis of conditions of the goods after which the new goods are delivered to the customers. From the viewpoint of manufacturers, additional logistical cost will occur in reverse logistics processes, and the goods can be broken in the logistics processes, followed by deteriorated quality. On the basis of the variance of logistics environment, reverse logistics occur more frequently compared with the past, but it is difficult to perform efficient logistics management because there is a lack of recognition in reverse logistics and the problems associated with the systems. Therefore, this study shows the needs and the classification of reverse logistics on the basis of the variance of logistics environment through prior research and suggests the methods of efficient reverse logistics management systems of 3PL service providers by analyzing the causes and problems of reverse logistics [4-6].

\section{Literature Review}

\subsection{PL Systems}

1) Introduction of $3 P L$

3PL service means that the logistics service providers perform whole or parts of logistics functions on behalf of the shippers (manufacturers and distributors) in supply chains from procurement of raw materials to consumption of final goods. 3PL is widely used due to the improvement of customer service and logistical cost saving as well as providing a solution to an insufficient logistics resource through outsourcing. When shippers introduce 3PL services, they receive proposals from logistics service providers and choose a 3PL provider through competitive bidding. 3PL, which means strategic alliance between shippers and logistics service providers, is a necessary requirement for information sharing and exchange that provides a win-win strategy associated with common goals. Information sharing is the most important factor for 3PL with contracts with partners [7].

3PL's aim is for shippers and logistics service providers to make common goals for logistics cost saving and logistics service improvement. In order to achieve their goals, their relationships are regarded as a strategic alliance that yields contract and share information. 3PL service providers provide shippers with sustainable improved logistics services from investigating the present conditions to planning, designing the structure of systems, and operations and performance management.

2) Structural Elements of 3PL Services

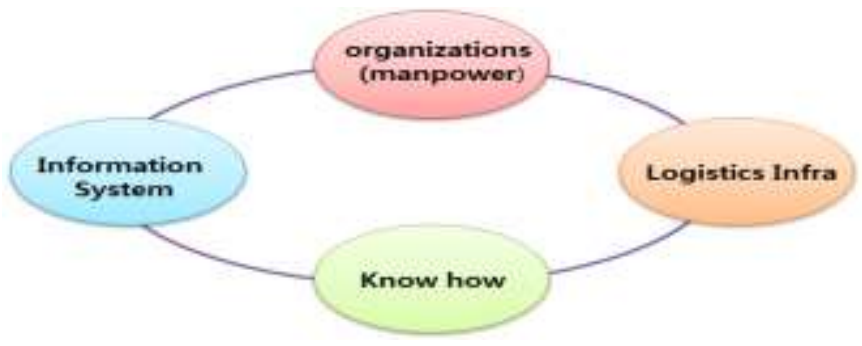

Figure 1. Structural Elements of Logistics Outsourcing 
The key structural elements for which logistics service providers perform logistics outsourcing from the viewpoint of 3PL services are classified into three factors: organizations (manpower), information systems and logistics infrastructure. Additional elements are included in the criteria of performance measurement in logistics services for which 3PL provide customers and accumulate operational logistics capabilities for a long time [8]. First, organizations for logistics outsourcing are divided into an operational organization for logistics works, sales organization, a consulting organization and an organization of information systems. It is important to sustainably provide and create a value of costs and services promised to customers on the basis of flexible co-operation among organizations. Logistics service providers need to provide capabilities for total solution resulting in whole optimization within logistics systems such as logistics investigation, consulting, proposals, restructuring of logistics works, the building and performing of systems, aftercare service and improvement of logistical activities. Considering the scope of logistics, required outsourcing to logistics service providers is expanded from management and operations in a logistics unit to optimal supports of logistics works such as strategy, management and information. Second, information systems are included in the systems for co-operations and information sharing with customers and partners as well as internal operational systems. The major information systems to perform outsourcing are divided into order management systems (OMS), warehouse management systems (WMS), transport management systems (TMS), location-based systems (LBS) and enterprise resource planning (ERP). The goal of information systems is to improve work efficiency and to enhance work cooperation through structuring efficient information connection systems between systems of customers and partners and systems of logistics service providers. WMS and TMS are logistics performing systems for optimal management of warehouse logistics and transport vehicles. WMS supports input and output of warehouse logistics, storage management, real-time confirmation of storage information and optimal operations of workers and equipment in warehouse logistics. TMS performs chasing goods and management of transport cost and supports transport plans, routs, and consolidation of goods through optimal algorithm. The last key factor is logistics infrastructure. It consists of warehouse logistics, terminals for goods, transport, loading/unloading, storage, facilities of transport and so on. There are two kinds of logistics firms such as an assetbased and a non-asset based, and logistics infrastructure is included in the former. Nonasset based logistics firms that provide 3PL logistics service use logistics infrastructure of many logistics firms and that is why they require the integration of works and information technology or the abilities of connection among partners. In addition, they have the needs to acquire logistics information systems which have flexible and opened architecture on the basis of Internet for cooperation among firms.

3) The Process of 3PL Systems

3PL systems provide customers with total logistics services on logistics works such as order management, stock management, manufacturing and distributing, inbound and outbound management, transport management, indices management and logistics consulting. Figure 2 shows the process of 3PL systems [9].

3PL provide efficiencies to customers and offer quick logistics works by integrating OMS, WMS, TMS and LBS. In addition, they are able to manage the indices needed by the customers within the information systems and operate customer support systems via web that is easily approachable by the customers. Furthermore, outsourcing the logistics which is a non-core competence, customers can increase productivity through focusing on core competence based on selection and concentration as well as save logistics cost and increase customer services. 


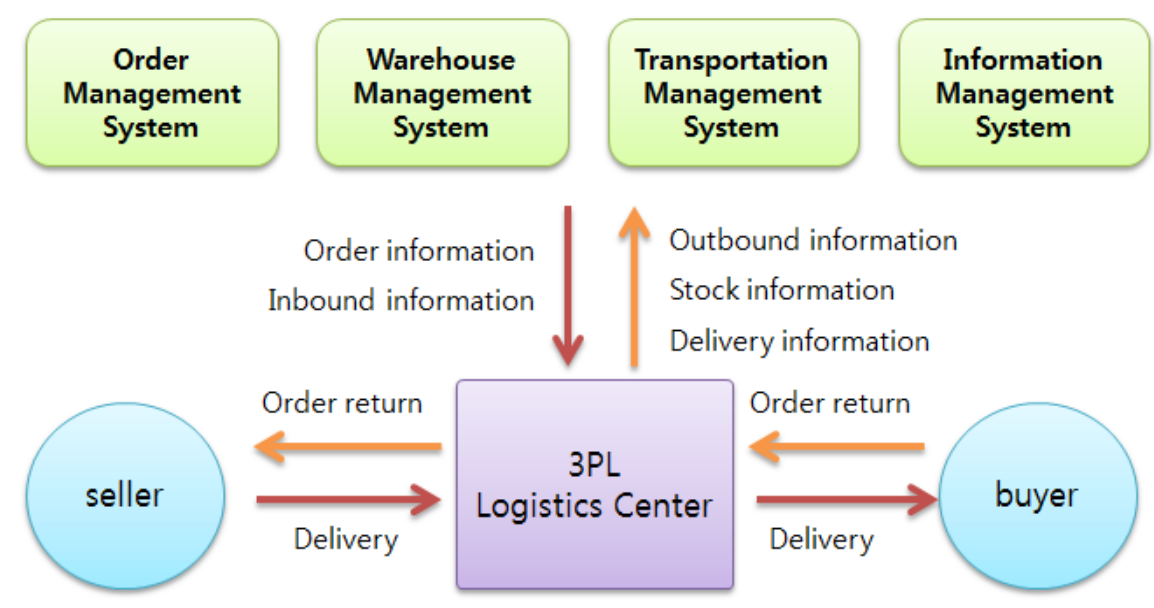

Figure 2. 3PL System Process

\subsection{Reverse Logistics Systems}

1) The Definition and Kinds of Reverse Logistics

Logistics pertains to the consecutive flow of products from suppliers to consumers. On the other hand, reverse logistics is performed at reverse direction with physical distribution from consumers to suppliers. Suppliers in reverse logistics recover goods from consumers and decide whether to re-use or dispose the returned products based on the condition of the goods. Therefore, reverse logistics is defined as all activities concerned with reuse of products and materials. There are three kinds of reverse logistics such as return logistics, collect logistics and disposal logistics. Figure 3 shows the types of reserve logistics [10].

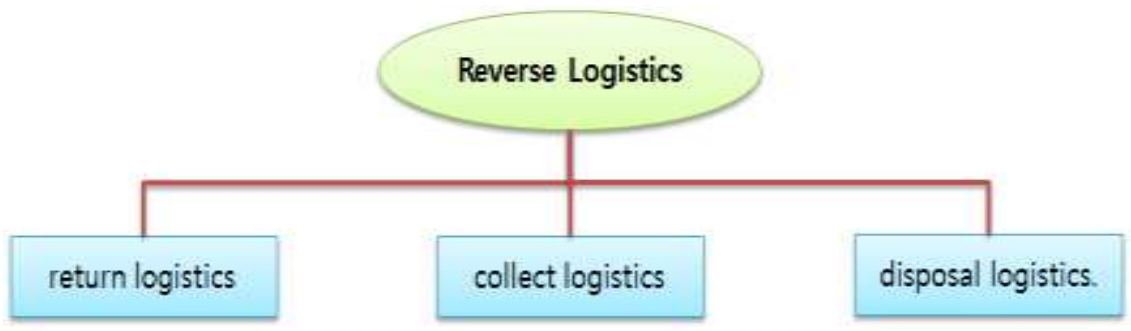

Figure 3. Types of Reverse Logistics

Return logistics is a process where the suppliers perform exchange of goods as well as provide refunds to customers and recover the goods when goods are defective. Collect logistics is concerned with all activities; specifically, it is when customers return the goods to manufacturers for exchange, refund or repair. Disposal logistics is logistics activity with the goal of treatment for abandoned goods.

\section{2) Prior Research on Reverse Logistics}

There are many research papers concerned with efficient management methods for reverse logistics because the attention of reverse logistics has recently increased. Fleischmann et al., (1997) suggest distribution planning, inventory management and production planning of reverse logistics on the basis of literature review. Cho et al., (2003) explain that the development of electronic commerce can be an alternative to solve the problems of reverse logistics. Lim et al., (2006) analyze the introductive effect of reverse logistics through the simulation model of closed loop which can analyze the effect of reverse logistics on re-using parts in car industry. Lim et al., (2006) suggest efficient 
management method for minimizing reverse logistics in electronic commerce. Mitra (2009) explains the introduction of multi-echelon systems concerned with returned goods and suggests efficient managing method of returned goods compared with single-echelon systems. Kwon (2012) explains the present conditions and a problem of reverse logistics in electronic industry compared with oversea cases and suggests improved methods of structuring information systems for integrated management and reverse logistics processes for disposal of home electronic goods. Lee et al., (2014) suggest the mathematical model for efficient re-treatment through re-adjusting location of recycling centers from the viewpoint of cost and moving distance. Yun (2015) makes reverse logistics networks on treatment processes of life wastes and suggests the methodology to totally consider treating cost, fixed cost and transport cost to improve reverse logistics networks. Yun (2016) suggests an integrated logistics model to consider reuse, re-sale and waste disposal of recovery goods to use the closed-loop supply chain model.

\section{3) The Problems and Processes of Reverse Logistics Systems}

Recently, reverse logistics has become one of the factors to maintain competitive advantages in firms and as a result, it is more important than ever. Product life cycle is shorter and shorter, and firms perform exchange, return and refund from the viewpoint of improving customer service. As a result, 3PL has an important role in reverse logistics. The goal of reverse logistics is to minimize costs that are occurring in returning of goods and recovery of value as much as possible when they occur. To achieve this goal of reverse logistics, the factors in Figure 4 should be included in the process of reverse logistics [11].

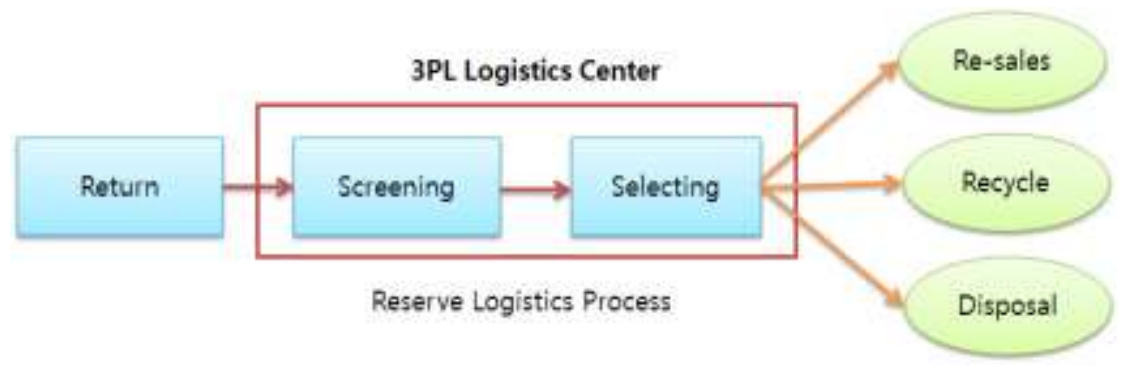

Figure 4. Process of Reverse Logistics

Screening as the first step of reverse logistics is concerned with selecting goods. In the second step, shippers divide goods into re-use or disposal. Accurate judgement can save cost in the third step. After a selection process, return goods are put in collection and sorting process occurs in the fourth step. After finishing the steps, the goods are finally treated for disposition. The goods are then sent to returns, re-sales, sales to outlet malls, discount shops or markets, donation, repair and disposal on the basis of the condition.

There are various problems in reverse logistics. First, the time of reverse logistics is not certain. The time is different with each customer because customers make a decision for returns after purchasing and feeling dissatisfied. In addition, because the characteristics and conditions of the goods are different and unpredicted, this can decrease the efficiency of logistics. Second, reverse logistics for returns generally spend high logistics cost because it is difficult to collectively treat the products on the basis of the various requests made by the customers. Third, in reverse logistics processes, logistics service providers should be flexibly connected with each other in each logistics process. Fourth, the time in reverse logistics is more important than the time in forward logistics. The longer the lead time, the lower the quality of the product and the more customer complaints about the reverse logistics. Fifth, it is difficult to acquire visibility on the goods because the goods have already been sent to the manufacturers. Forward logistics has already attained 
logistics efficiency to use logistics information systems, but it is difficult to acquire visibility in reverse logistics because of its solitary and uncertainty in the goods. Sixth, the satisfaction of reverse logistics has an effect on the goods and the firms, followed by the re-purchase and the brand image.

\section{The Method of Design and Structure of Efficient Reverse Logistics Systems for 3PL Service Providers}

1) The Process of Reverse Logistics System by 3PL Service Provider

Reverse logistics service of 3PL systems starts from requesting returns and recovery by partners. Figure 5 shows the process of reverse logistics systems for 3PL service providers [2].

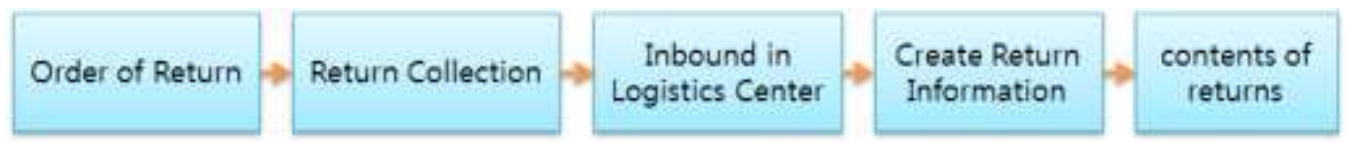

Figure 5. Process of Reverse Logistics Systems for 3PL

When partners require returns, logistics centers take over the order for returns. The operator of 3PL service providers needs to clearly regulate the reasons for returns. Transporters should confirm whether the content of returns is equal to the goods of the returns when they pick up the goods. The collected goods are divided into level A, level B or level $\mathrm{C}$ on the basis of the principle of classification or rules of returns set by the manufacturer. Level A goods are moved to warehouses, level B goods are divided into good conditions or bad conditions, and level $\mathrm{C}$ goods should be disposed. The disposal is performed in order abide by the manufacturer's disposal policy. After the process, the operators of 3PL service providers compile the information and the contents of returns. The contents consist of quantities, levels, manufacturers, the date of returns and the total quantities of returns for each manufacturer. Finally, the operator sends the results to the manufacturers along with the contents of the returns.

2) The Structure of Database for Reverse Logistics Systems by 3PL Service Provider

Various processes are needed in the structure of 3PL reverse logistics systems.

Figure 6 shows the process of structuring 3PL reverse logistics systems. The staff performs the analysis of database and processes concerned with the requirements of clients and the analysis of environment on 3PL reverse logistics systems after which the systems are developed. In the processes of the requirements and the analysis of environment, the system is designed after the staff classifies the data analysis and the process analysis on the basis of the requirements for works requested by participants and users of 3PL logistics systems. The first step of data analyses is data modeling. Data modeling is concerned with deciding what kind of information they will need in order to structure database systems. It is a figure that analyzes the relationships between data. The process of entity relationship diagram (ERD) is required for efficiently processing data modeling [13]. ERD is used to verify the relationships between entities, to define directions and despondence value after deciding the names of the relationships, and to draw diagrams and lines on the basis of the definitions. In the step of database design, the real table of database is made and the database is designed and structured through data modeling. A process analysis is also similar with the process of data analysis. The developers develop connecting data analysis with process analysis when making real systems [14]. 


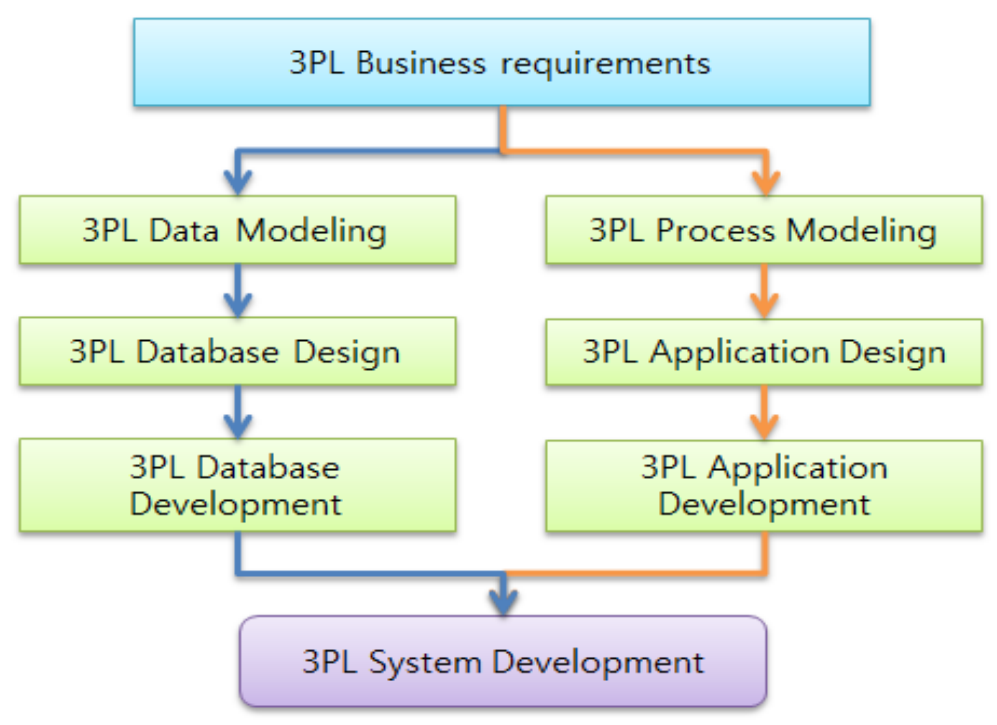

Figure 6. Process of Structuring 3PL Reverse Logistics Systems

The staff should define the field names and the tables to design database of 3PL reverse logistics systems. The database tables consist of a business area information table (TB_UNTMSTINFO), clients' information table (B_CSTMSTINFO), information for clients' returns center (TB CSTRGCINFO), clients' goods information (TB_CSTITMINFO), users' information (TB_USERINFO) and the lists of returns (TB_RTGOODHIS) and the database is designed. Table 1 shows database table in 3PL reverse logistics systems. Table 2 shows field name of TB_CSTITMINFO. Figure 7 shows ERD database of 3PL reverse logistics systems [15].

Table 1. Database Table of 3PL Reverse Logistics Systems

\begin{tabular}{|l|l|l|}
\hline No & Table name & contents \\
\hline 1 & TB_UNTMSTINFO & Business Information \\
\hline 2 & TB_CSTMSTINFO & Customer Information \\
\hline 3 & TB_CSTRGCINFO & Customer Return Logistics Center Information \\
\hline 4 & TB_CSTITMINFO & Customer Return Goods Information \\
\hline 5 & TB_UNIMST1INFO & General Information \\
\hline 6 & TB_USERINFO & User Information \\
\hline 7 & TB_RTGOODHIS & Return Goods Contents \\
\hline
\end{tabular}

Table 2. Filed Name of TB_CSTITMINFO

\begin{tabular}{|l|l|l|l|l|l|}
\hline No & Field name & contents & type & size & remark \\
\hline 1 & ITM_CD & Item Code & VarChar & 20 & Primary Key \\
\hline 2 & ITM_NM & Item name & VarChar & 50 & \\
\hline 3 & ITM_UNIT & Item Unit & VarChar & 10 & \\
\hline 4 & ITM_TYPE & Item type & VarChar & 20 & \\
\hline 5 & CST_CD & Costumer Code & VarChar & 10 & \\
\hline 6 & LOCATION & Location & VarChar & 20 & \\
\hline 7 & ITM_BARCODE & Item barcode & VarChar & 20 & \\
\hline 8 & REMARK & special note & VarChar & 50 & \\
\hline
\end{tabular}




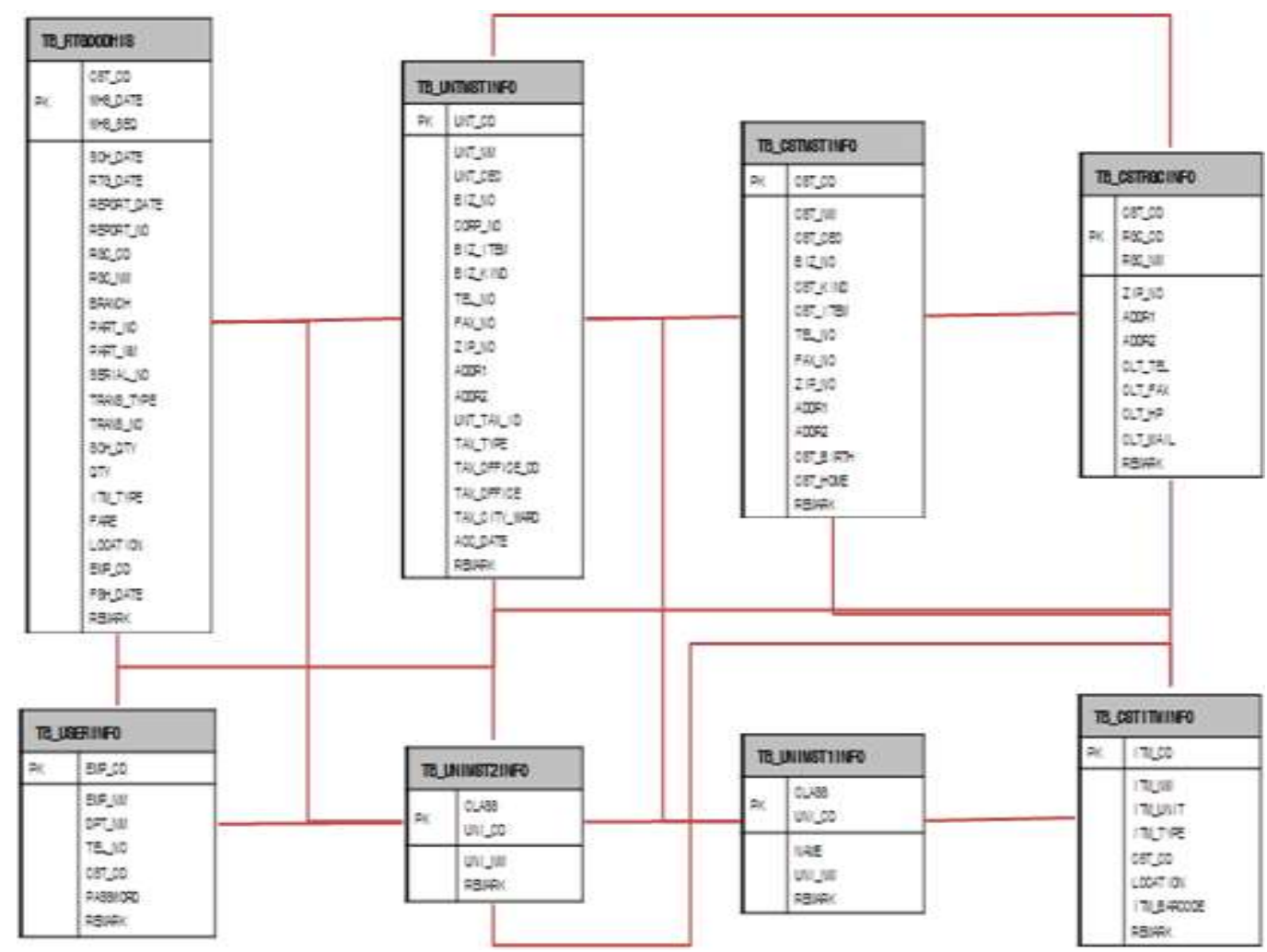

Figure 7. ERD Database of 3PL Reverse Logistics Systems

3) The Structure of Reverse Logistics Systems for 3PL Service Provider

The contents of 3PL reverse logistics systems are as follows:

The staff takes over the order of returns in logistics centers and develops the systems that can clearly regulate the reasons of returns. In addition, transporters need to confirm whether the goods in the list is equal to real returned goods when they pick up the goods. The staff of 3PL service providers should gather the information of the returned goods, record quantities of returned goods, the level of the goods, manufacturers and the data of returns, and write the lists of returns. The staff can automatically register the lists of returned goods in an EXCEL format, and it is also possible to manually register the lists. Manufacturers can check the lists of returned goods in real time.

Figure 8 and Figure 9 represent the information of the goods returned and manufacturer's registration of returned goods. When the registration of returned goods is performed, the staff can choose manufacturers in the log-in process, select information of goods, and choose goods in the registering process.

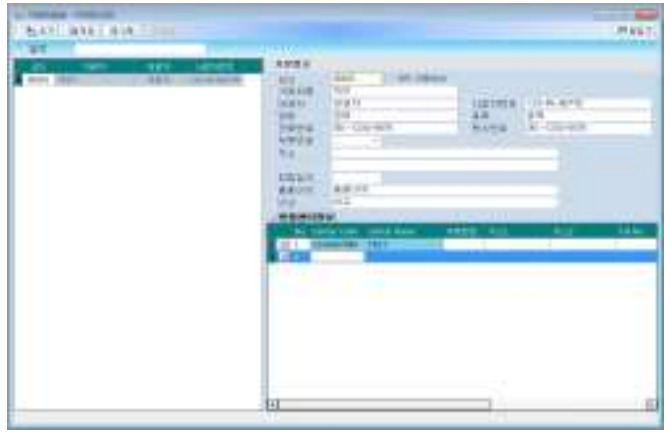

Figure 8. Returned Goods Information

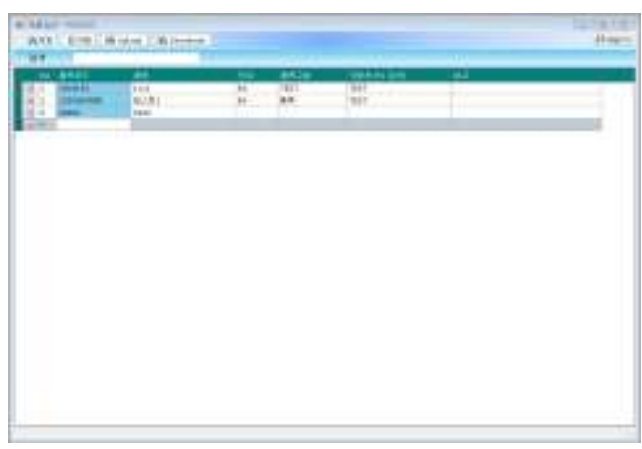

Figure 9. Registration 
Figure 10 and Figure 11 show users' information and general complex information.

The information of users can be automatically uploaded as EXCLE files. When returned goods are registered in general complex information, users can choose the sort of transport and the condition of goods.
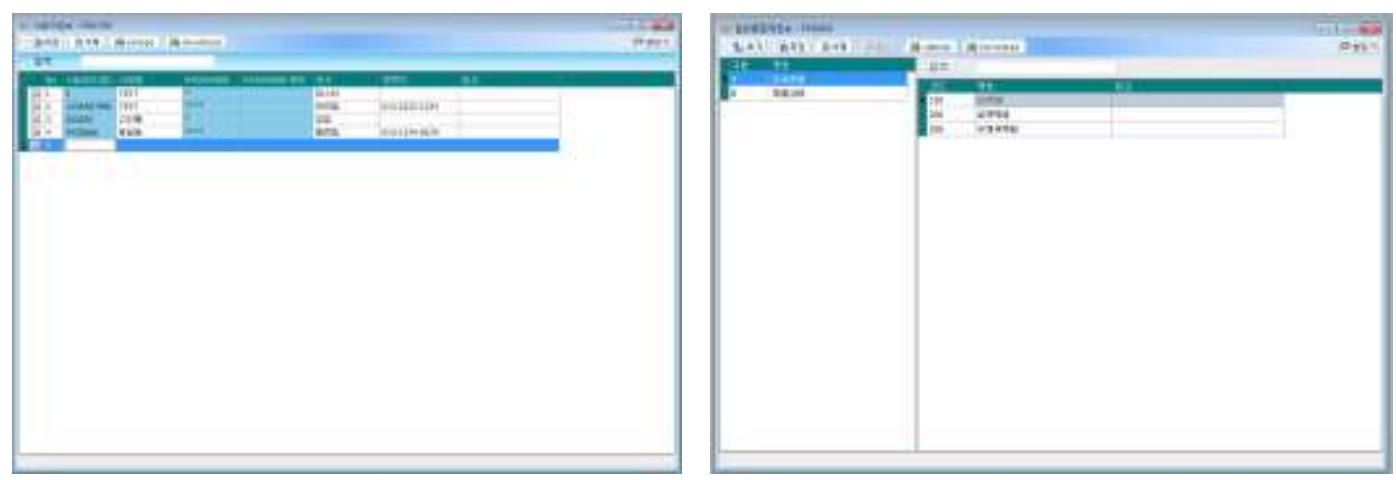

Figure 10. Users' Information

Figure 11. General Complex Information

Figure 12 and Figure 13 represent the present conditions of returned goods and registering returns. The staff registers inbound data, reporting data, transporters and the conditions of returned goods in the registering returns and searches for the specifications of returned goods on the basis of the terms of returns in the present conditions.
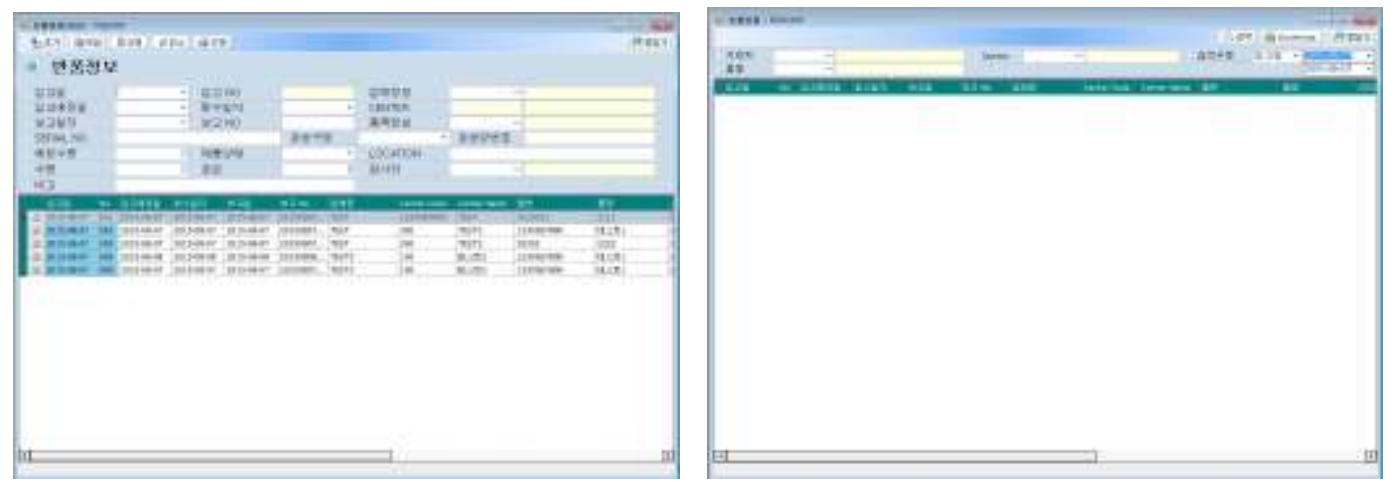

Figure 12. Conditions of Returned Goods Figure 13. Registering Returns

\section{Conclusion}

Shippers spread the position of 3PL in the internal logistics in order to follow the variance of logistical environment like multi-products small quantity delivery. In addition, there is the high frequency of reverse logistics such as returns and exchanges on the basis of customer needs.

This study suggests the method of structuring reverse logistics systems for 3PL firms. To develop the systems, this study performs data analysis and process analysis on the basis of the requirements of 3PL reverse logistics systems. The step of the data analysis is connected with designing and structuring database after processing data modeling. The step of analyzing the process is concerned with developing applications after designing applications and modeling the process. To simultaneously consider data analysis and process analysis, these studies produce whole 3PL reverse logistics systems.

It is possible for structured 3PL reverse logistics systems to save logistics cost and to improve customer service through decreasing lead time on reverse logistics. The systems can guarantee the allocation of stable benefits to both manufacturers and 3PL service providers. There are several future research directions such as structuring reverse logistics 
systems for whole supply chain management (SCM), saving reverse logistics cost for SCM and decreasing lead time of reverse logistics in SCM.

\section{Acknowledgments}

"This Research was supported by the Tongmyong University Research Grants 2017 (2017A025)".

\section{References}

[1] Y.-S. Kwon and M.-T. Kwon, "An Effects of 3PL Service Quality and Relationship Quality on the Logistics Performance", Journal of Distribution Research, vol. 15, no. 5, (2010), pp. 19-35.

[2] H.-J. Cho and S.-s. Kim, "Factors Affecting Transaction Costs in Logistics Outsourcing: From the Perspective of Third Party Logistics", Journal of the Korean Society of Supply Chain Management, vol. 17, no. 2, (2017), pp. 1-17.

[3] I.-S. Sun, "A Political Proposal for the Reverse Logistics Activation", Journal of Distribution Research, vol. 15 , no. 5, (2010), pp. 61-79.

[4] C.-B. Kim and S.-H. Kwon, "An Empirical Study on the Determinants of e-Reverse Logistics's Business Performance", The e-Business Studies, vol. 11, no. 4, (2010), pp. 51-70.

[5] Y.-R. Kang, S.-H. Moon and C. Park, "The Influential Factors of the Return Behavior in TV HomeShopping”, Asia-Pacific Journal of Business \& Commerce, vol. 1, no. 1, (2009), pp. 83-99.

[6] J.-S. Lim, S.-J. Jeong and K.-S. Kim, "The Effect of Reverse Logistics with Simulation Method -An Example from the Automotive Industry-", Journal of the Korea Society for Simulation, vol. 15, no. 2, (2006), pp. 13-21.

[7] S.-M. Jung and C.-B. Lee, "A Study on Global Supply Chain Design and Competitive Strategies for Korean Third Party Logistics Service Providers", Korea trade review, vol. 38, no. 5, (2013), pp. 233-255.

[8] K.-u. Kim, "A Study on AHP-based Third Party Logistics Service Strategy", Graduate School of Marine Finance and Logistics, Korea Maritime and Ocean University, (2017).

[9] Y.-S. Yun and X. Chen, "An Efficient Methodology for Daily Waste Treatment Using Reverse Logistics Network: Focused on D Metropolitan City", Journal of the Korea Industrial Information Systems Research, vol. 20, no. 2, (2015), pp. 97-111.

[10] Y. T. Yim and S. A. Seo, "Study on methods of minimizing the reverse logistics in e-Commerce Focused on the B2C -", Journal of Korea Port Economic Association, vol. 24, no. 3, (2008), pp. 147165.

[11] F. Du and G. W. Evans, "A Bi-Objective Reverse Logistics Network Analysis for Post-Sale Service", Computers \& Operations Research, vol. 35, no. 8, (2007).

[12] H. Min and H.-J. Ko, "The Dynamic Design of a Reverse Logistics Network from The Perspective of Third Party Logistics Service Providers", International Journal of Production Economics, vol. 113, no. 1, (2007).

[13] W. Lee and H. Lee, "Performance Evaluation of Coordinated Multi-Point Transmission and Reception in Indoor Mobile Communication Systems", JICCE, vol. 11, no. 3, (2013), pp. 167-172.

[14] D.-J. Park, Y.-S. Choi and J.-Y. Kim, "Establishment Efficient Logistics System for Components of Marine Equipment", International Information Institute, vol. 19, no. 7(A), (2016), pp. 2725-2730.

[15] D.-J. Park, H.-S. Bae and W.-S. Kim, "The Improving Methods of JIT Production Logistics Systems Interfaced with SAP”, International Information Institute, vol. 20, no. 8(A), (2017), pp. 5545-5550.

[16] H. Lee, "Why Mobile Operators Introduced Data Plans: An Analysis of Voice and Data Usage Patterns", JICCE, vol. 14, no. 1, (2016), pp. 9-13.

[17] Y. Hak Kim, "Cluster-Based Quantization and Estimation for Distributed Systems", JICCE, vol. 14, no. 4, (2016), pp. 215-221.

[18] Y.-S. Yun, C. Anudari and X. Chen, "Hybrid Genetic Algorithm Approach using Closed-Loop Supply Chain Model", Journal of the Korea Industrial Information Systems Research, vol. 21, no. 4, (2016), pp. 31-41.

[19] Y.-S. Yun and X. Chen, "An Efficient Methodology for Daily Waste Treatment Using Reverse Logistics Network: Focused on D Metropolitan City”, Journal of the Korea Industrial Information Systems Research, vol. 20, no. 2, (2015), pp. 97-111.

[20] J.-m. Lee and H.-s. Kim, "A Study on Forecasting Models for the Processing Volume of End-of-Life Consumer Electronics at the Recycling Centers in Korea", Journal of the Korean Society of Supply Chain Management, vol. 14, no. 2, (2014), pp. 85-92.

[21] O-Young Kwon and Daejin Kim, "A Strategical Review on Reverse Logistics Promotion of Electronic Company Korean”, Journal of Business Administration, vol. 25, no. 2, (2012), pp. 1219-1236.

[22] S.-K. Lee, J.-W. Roh and Y.-B. Cho, "A Study on the Optimal Method for recycling the Waste Electronics` Reverse Logistics”, International Commerce and Information Review, vol. 16, no. 4, (2014), pp. 171-190. 
[23] M. Fleischmann, J. M. Bloemhof-Ruwaard, R. Dekker, E. van der Laan, J. A. E. E. van Nunen and L. N. Van Wassenhove, "Quantitative models for reverse logistics: A review", European Journal of Operational Research, vol. 103, (1997), pp. 1-17.

\section{Author}

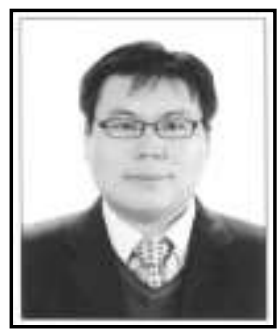

Doo-Jin Park, received a Ph.D. degree in the Department of Logistics System from the National Korea Maritime and Ocean University in 2007. He received his MS degree in the Department of Information Communication Engineering from Pukyong National University in 2002. He is a professor in the Department of Port Logistics System at Tongmyong University since 2011. His current research interests include IT Logistics, IoT, WMS, ERP, 3PL, SCM, Smart Factory and Smartphone App. 
International Journal of Advanced Science and Technology

Vol.119 (2018) 